\title{
"YO NO SOY UN GANGSTA". REPRESENTACIONES Y DISCURSOS SOBRE JUVENTUD(ES), VIOLENCIA(s) Y CULTURA(s)
}

\author{
“I'M NOT A GANGSTA". \\ RePresentations AND SPEEches about Youth(s), \\ Violence(s) and Culture(s)
}

\section{Lucía Abreu* Rocío Baquero $^{* *}$}

Resumen: El presente artículo propone reflexionar sobre los modos en que algunos jóvenes de sectores populares urbanos de la Ciudad Autónoma de Buenos Aires - CABA- Buenos Aires, Argentina, construyen su identidad en relación con la violencia y el delito en contextos de exclusión social a través del Hip Hop. La idea es indagar en los discursos y las prácticas culturales de un grupo de varones jóvenes que vive en el barrio de Villa Soldati —Comuna 8 de CABA — y se vincula en torno al Hip Hop, el cual se constituye en marca identificatoria que regula diversas dimensiones de la experiencia, modos de socialización y habitabilidad; al tiempo que funciona como escenario de disputa sobre el sentido de ser joven en contextos de violencia y vulnerabilidad. La propuesta se desarrolla con las herramientas propias del análisis comunicacional y cultural y la práctica etnográfica.

\footnotetext{
"Lic. en Ciencias de la Comunicación, Facultad de Ciencias Sociales, Universidad de Buenos Aires; Maestrante en Comunicación y Cultura, FSoc, UBA; Becaria doctoral, Instituto de Investigaciones Gino Germani, FSoc, UBA. Correo e.: labreu@sociales.uba.ar ${ }^{*}$ Lic. en Ciencias de la Comunicación, Facultad de Ciencias Sociales, Universidad de Buenos Aires; Becaria doctoral, Instituto de Investigaciones Gino Germani, FSoc, UBA.

Correo e.: rociobaquero@hotmail.com

Fecha de recepción: 2410 17; Fecha de aceptación: 150518.
}

(cc) EY-NC-ND Páginas 39-58. 
Palabras clave: sectores populares urbanos, jóvenes, cultura, Hip Hop.

Abstract: This paper reflects on the ways in which some young boys from poor urban sectors of Buenos Aires city, Argentina, build their identity through Hip Hop, in relation to violence and crime in contexts of exclusion. The proposal is to investigate the speeches and cultural practices of young boys who live in the neighborhood of Villa Soldati (Commune 8 of Buenos Aires city) and revolve around Hip Hop as an identifying mark that regulates various dimensions of experience, modes of socialization and habitability. At the same time it functions as a field of confrontation about the sense of being young in contexts of violence and social vulnerability. The proposal is developed with the tools of communicational and cultural analysis, and ethnography.

Keywords: poor urban sectors, youth, culture, Hip Hop.

\section{Introducción}

El interés que guía este trabajo es indagar en las representaciones que son producidas por ciertos varones jóvenes de Villa Soldati, situada en la Ciudad Autónoma de Buenos Aires, CABA; en los modos en que ellos construyen su biografía, narran sus trayectorias y describen la vida cotidiana en relación con el territorio que habitan y otros actores de la sociedad.

El trabajo de campo del que se presentan algunas aproximaciones forma parte de un estudio más amplio desarrollado por una de las autoras de este artículo, Lucía Abreu, en el marco de la tesis en proceso de la maestría en Comunicación y Cultura —FSoc, UBA-, cuyo tema es la violencia de la exclusión, y se titula "Vivir en la villa: un estudio sobre comunicación, identidades y violencias entre varones jóvenes de sectores populares urbanos que hacen Hip Hop en Buenos Aires y el Conurbano (2014-2016)”. 
El abordaje metodológico es cualitativo porque el artículo se pregunta por el sentido de los modos en que jóvenes villeros que hacen Hip Hop comunican su identidad y la construyen en la resistencia a la precarización y vulneración de sus vidas y sus derechos. Se trata de un diseño de investigación que al mismo tiempo es flexible porque no busca una contrastación empírica sino explicar los sentidos de prácticas e identidades, por lo anterior se recurrió a la etnografía como teoría y como método para observación y registro de prácticas de los informantes, interacciones, relatos de vida y conversaciones informales como así también entrevistas de oportunidad. El corpus de estudio lo constituyen los datos resultantes de los testimonios de un grupo de varones jóvenes que hace Hip Hop, habitantes de las villas Los Piletones y Fátima —Villa Soldati, CABA—; como así también del organizador y asistentes al Festival de RAP Mi cara, mi ropa y mi barrio, no son delito — evento barrial e itinerante-; y por último, se incluyen algunas letras de raps y traps. Se realizaron treinta entrevistas abiertas en profundidad — de ahora en adelante, "entrevistas" —, al mismo tiempo que se conversó "informalmente" con raperos y con sus públicos y fans, registrando su interacción.

Aquel trabajo de campo fue necesario para comprender las experiencias de vida de ciertos jóvenes de sectores populares que dicen cómo sus derechos son vulnerados, e intentar explicar cómo viven las desigualdades sociales, económicas y culturales, la exclusión educativa y laboral, para interpretar cómo construyen su identidad en ese contexto.

Por lo tanto, la propuesta es problematizar el vínculo entre estos varones jóvenes de sectores populares urbanos, la música, y la violencia. $\mathrm{Al}$ mismo tiempo es relevante abordar el reconocimiento del Hip Hop dentro del arte musical, que excede el propio espacio de gestación. En estas breves líneas se propone dar cuenta del significado que la música otorga a la precariedad del territorio que habitan estos jóvenes, las relaciones entre pares y con los otros, que inevitablemente se distingue por la misma precariedad de lazos institucionales, y también se refiere a la perseverancia, ya que los jóvenes artistas que son objeto de este estudio buscan incorporarse al campo de la industria cultural, situación que sólo unos pocos logran. Los jóvenes que hacen Hip 
Hop ven su música como legítima, la "única” para "dar combate” a la marginalidad y al mundo de adicciones, según nuestros informantes, los cuales organizan talleres y festivales barriales itinerantes de Hip Hop contra la violencia institucional.

\section{Juventud(es) y derechos en contexto}

En Argentina, según datos del Censo del año 2010, más de 25\% de la población total —40,117,096 de habitantes_ eran menores de 15 años; en tanto la franja entre 15 y 24 años alcanzaba $16 \%$. En CABA ${ }^{1}$ dicho segmento abarca $13,7 \%-395,806$ de un total de 2,891,082 de habitantes_- La Comuna 8 de esta ciudad, ${ }^{2}$ en donde se realizó el trabajo etnográfico, está compuesta por tres barrios: Villa Lugano, Villa Riachuelo y Villa Soldati. Según estadísticas provistas por el gobierno de la ciudad en 2011, la población asciende allí a 190.992 personas. Dicha Comuna fue la que registró el mayor incremento de la población, 7\%, respecto del censo realizado en la ciudad en 2001. Los datos señalan que el crecimiento poblacional está relacionado con el aumento de la población residente en villas y asentamientos precarios.

Del documento "Diagnóstico de la Ciudad de Buenos Aires, ¿¿cómo está tu comuna?” (2011) se desprende que la Comuna 8 es una de las que posee mayor porcentaje de hacinamiento $-17,6 \%$ de hogares con 2 a 3 personas por cuarto y $4 \%$ con más de 3 personas-. A su vez, uno de cada tres habitantes reside en villas o asentamientos, así la Comuna tiene el mayor porcentaje de habitantes en esa situación. Con respecto al acceso a los servicios básicos, sobresale el hecho de que 36,4\% de los hogares no accede al gas de red - en contraposición con el promedio, $7,8 \%$ - En materia de educación la zona registra el mayor porcentaje de población mayor de 25 años que no terminó el primario, 9,8\%, y más de la mitad no logró finalizar el nivel secundario, 53,5\%. Estudios del Ministerio Público Tutelar de la Ciudad de Buenos Aires, sobre

${ }^{1}$ La Ciudad de Buenos Aires se encuentra organizada en 15 Comunas que se rigen bajo la Ley 1.777 sancionada en 2005. Se trata de unidades descentralizadas de gestión política y administrativa que, en algunos casos, abarcan más de un barrio porteńo.

${ }^{2}$ La tercera parte de la población vive en la Comuna 8, donde se ubican seis villas - 3, 15 , 16, 17, 19, 20-, un núcleo habitacional transitorio - Av. del Trabajo-, y seis asentamientos - Scapino, Hubac, Bermejo María Auxiliadora-Barrio Obrero, Los Pinos-Portela, Los Piletones, Calacita. 
este caso, dan cuenta de la ausencia de establecimientos educativos de nivel medio y la consecuente falta de vacantes para las y los adolescentes residentes en la zona. Por otra parte, destacan la caída importantísima de la matrícula a lo largo de la trayectoria escolar en el nivel medio. La cobertura de salud también presenta índices problemáticos, se trata del mayor nivel de población que no está cubierta por obra social o prepaga, 40,9\%. Asimismo, en relación con la accesibilidad, hay un déficit en términos de conectividad con el resto de la ciudad, ya que si bien existe una red de colectivos que cubre la zona, su oferta es escasa, se encuentra concentrada en pocas líneas y es poca su frecuencia. ${ }^{3}$ Según la guía de establecimientos de la Ciudad, existen dieciocho entidades deportivas — tres con estadios de fútbol—y nueve establecimientos públicos culturales — cuatro bibliotecas y cinco centros culturalesen la Comuna. Por otra parte, hay 63 entidades no gubernamentales registradas, desde asociaciones civiles hasta organizaciones sociales de derechos humanos, religiosas, educativas, etcétera.

Los datos mencionados si bien pueden sufrir algunas variaciones en la actualidad evidencian que los territorios en los que los jóvenes desarrollan las prácticas culturales que son objeto de este estudio presentan las mayores condiciones de vulnerabilidad social en la ciudad. El contexto actual, a nivel país, presenta un panorama desfavorable en lo referido a que niños y jóvenes encuentren sus derechos plenamente garantizados: el documento "La pobreza monetaria en la nińez y la adolescencia en argentina” publicado por Unicef en 2017 destaca que $47,7 \%$ de los chicos en argentina viven en la pobreza, de los cuales 1,3 millones crecen en la pobreza extrema. Los más vulnerables son los adolescentes entre 13 y 17 ańos, especialmente aquellos que sus padres están desocupados o poseen bajo nivel de escolarización y en los casos en que sólo está la madre al frente del hogar. El estudio fue realizado con base en datos de la Encuesta Anual de Hogares del Instituto Nacional

\footnotetext{
${ }^{3}$ Para entender que hay zonas de Buenos Aires a las que no llega un transporte público, a fin de sintetizar las posibilidades de interacción que tienen los habitantes de la villa con la ciudad y la ciudad con la villa, quienes viven allí o quienes quieran llegar a Villa Soldati pueden hacerlo con los colectivos [autobuses] 150, 101, 143 por el Metrobus — sistema de carriles exclusivos para autobuses - y luego caminar cinco cuadras, combinar dos líneas de colectivos o usar la línea E de subte en combinación con el Premetro hasta la estación Nuestra Señora de Fátima.
} 
de Estadísticas y Censos (INDEC) en el cuarto trimestre de 2016, de allí también surge que la asignación universal por hijo ${ }^{4}$ reduce $30,8 \%$ la pobreza extrema, pero en menor medida la pobreza general que sólo desciende alrededor de 5\%.

El contexto socioeconómico es una aproximación ineludible para dar cuenta de los escenarios en los que se juega la identidad cultural de los jóvenes. Más allá de que la categoría "juventud" se clasifique en organismos nacionales y supranacionales como la población perteneciente a la franja etaria comprendida entre los 15 y 24 años, asociada únicamente al dato demográfico la noción de juventud se encuentra notablemente reducida y es un aspecto insuficiente para explicar las múltiples dimensiones que la atraviesan; especialmente si queremos reflexionar sobre la identidad concebida como "relacional", algo que se construye y se reconstruye constantemente en los intercambios sociales (Cuche, 1996). En esta orientación, siguiendo a Reguillo (2012), la juventud se conceptualiza como un producto histórico que no se agota en el referente biológico:

Son tres procesos los que otorga una mayor visibilidad a los jóvenes en la última mitad del siglo XX: la reorganización económica, como resultado del aceleramiento industrial científico y técnico, que implicó ajustes en la organización productiva de la sociedad; la oferta y el consumo cultural, y el discurso jurídico. A través de estos procesos, la noción de edad alcanza una densidad que no se agota en el referente biológico ... no es una categoría cerrada y transparente: queda relativizada cuando se establecen distinciones principalmente en función de los lugares sociales que ocupan los jóvenes (Reguillo, 2012: 23).

\footnotetext{
${ }^{4}$ La asignación universal por hijo para protección social es un seguro social de Argentina que otorga a personas desocupadas, que trabajan empleados en negro o que ganan menos del salario mínimo, vital y móvil, un beneficio por cada hijo menor de 18 años o hijo discapacitado - hasta 5 niños- La administradora de Asignación Universal por Hijo (AUH) es la Administración Nacional de la Seguridad Social (Ansés), que además emite la Libreta de la seguridad social, salud y educación, un documento que funciona como instrumento de control ya que debe ser presentada anualmente para demostrar el cumplimiento de los controles médicos, vacunación, inscripción al Plan Nacer y la asistencia regular a la escuela pública.
} 
Una definición más amplia permite considerar la noción de juventud en plural, "juventudes múltiples", coincidiendo con aquellos que han dado cuenta de la juventud como una condición social históricamente construida y atravesada por diversas variables sociales y culturales:

No existe una única juventud: en la ciudad moderna las juventudes son múltiples, variando en relación a características de clase, el lugar donde viven y la generación a que pertenecen y, además, la diversidad, el pluralismo, el estallido cultural de los últimos años se manifiestan privilegiadamente entre los jóvenes que ofrecen un panorama sumamente variado y móvil que abarca sus comportamientos, referencias identitarias, lenguajes y formas de sociabilidad. Juventud es un significante complejo que contiene en su intimidad las múltiples modalidades que llevan a procesar socialmente la condición de edad, tomando en cuenta la diferenciación social, la inserción en la familia y en otras instituciones, el género, el barrio o la micro cultura (Margulis y Urresti, 1998: 4).

Las expresiones juveniles no pueden entenderse por fuera de la cultura en las que están insertas y de las transformaciones políticas y sociales que allí transcurren. La cultura se entiende aquí desde una perspectiva gramsciana, esto es, política, como campo de lucha por la apropiación de sentido; y que funciona como espacio simbólico en el que los jóvenes reconocen y defienden sus derechos, fortalecen su acción social y política y crean lazos comunitarios. En esta clave, en el caso del que se ocupa este artículo sostenemos que los jóvenes se apropian del Hip Hop como un elemento constitutivo de su identidad que les posibilita producir sentido respecto de lo que significa ser joven con derechos vulnerados en la realidad contemporánea.

\section{Modos de habitar el territorio}

La exclusión social, espacial y económica, crea una situación de desigualdad en las vidas de muchos jóvenes que conviven a diario con las desventajas derivadas de la "discriminación estructural" (Kessler, 
2012). Brian 5 es un joven de Villa Soldati y pasa sus días, tal como él sostiene, "de la casa al trabajo, del trabajo a la plaza y de la plaza a su casa”. La plaza es el epicentro donde confluye con sus amigos de la villa — barrio vulnerado/gheto-, Elio, Aníbal y Dj Leica, alrededor de las seis de la tarde para realizar una actividad artística en común: freestyle, un estilo libre del rap que se caracteriza por la improvisación, similar al género "payada" aunque de connotaciones más agresivas y temáticas de la vida urbana. La plaza aparece como ámbito de uso privilegiado de constitución identitaria donde a través del Hip Hop estos jóvenes de sectores populares expresan su realidad y denuncian desigualdades e injusticias sociales:

La cumbia villera, el funk carioca, el hip hop norteamericano o el punk británico son todas expresiones de la política juvenil. Son ritmos que llaman al desorden y reavivan los espacios subterráneos y las zonas periféricas: agregan palabras a la ciudad, cambian la radiografía urbana con nuevas actitudes y pasos de baile. Hablan de las vinculaciones entre la juventud y el delito, pero también visibilizan un conflicto que no es nuevo. Desdramatizan la prebenda clasemediera criminalizadora de la identidad juvenil (Roldán, 2017: 206).

El Hip Hop surge en los ańos 60 en el barrio del Bronx de Nueva York, Estados Unidos, y fue Afrika Bambaataa, nacido y criado en Nueva York, el primero en acuñar el término, en armar encuentros para fomentar la no-violencia entre los jóvenes, luchar contra los conflictos territoriales que arrasaban a los barrios vulnerados y denunciar las injusticias sufridas por los jóvenes de los guetos. Aquellos encuentros se distinguían por expresarse a través del Breaking - break dance, danza urbana-, Djing — disc jockey_, MC — raperos, antantes—, y el Grafiti — pintura libre, destacada por su ilegalidad-, que

${ }^{5}$ Los nombres de los registros de campo son ficticios para resguardar la integridad de los entrevistados. No obstante, mantuvimos los nombres reales de los músicos, raperos y bandas citadas que fueron nuestros informantes por expreso pedido de ellos, porque celebran ser quienes son y quieren ser "famosos", reconocidos en el mainstream o al menos en el ambiente del Hip Hop. ${ }^{6}$ Improvisación de versos con acompañamiento de guitarra que hace un orador; generalmente los versos relatan sucesos o sentimientos de la cotidianidad rural, y pueden tener un carácter lírico, trágico o humorístico. 
fueron los cuatro elementos — disciplinas - que de alguna manera estructuraron al Hip Hop hasta el día de hoy. A través de ellos se busca difundir el Hip Hop, revitalizar el tejido social y, en el mejor de los casos, reconstruir los vínculos comunitarios. Para Castillo-Garsow y Nichols (2016) el intercambio cultural se ha expandido en las últimas décadas: la música que viaja de Estados Unidos a Latinoamérica y de regreso como artistas visuales, productores de música, MC, vocalistas y bailarines, combinan sus culturas latinas con influencias del norte de la frontera estadounidense para crear nuevas experiencias artísticas. Concretamente, en Argentina el ritmo penetra en la década del 90 con El Sindicato Argentino del Hip-Hop y La Organización, con Mustafá, ${ }^{8}$ los primeros grupos de la escena local.

Brian integra una crew con la cual compone temas, arman las bases instrumentales y organizan talleres de rimas para los más pequeños y principiantes. Las crews comienzan a agruparse por una cercanía geográfica, como puede ser el barrio, "un barrio puede ser solo dos cuadras, o una esquina o un territorio municipal, según quien lo habite. Las variadas formas de renombrar y recorrer el barrio nos hablan de la multiplicidad de formas de vidas barriales, de los distintos cuerpos que aguantan por ahî" (Colectivo de Juguetes Perdidos, en Roldán, 2016: 212) y luego pueden incorporar a algún conocido o familiar que no viva en él, aunque el común denominador es el barrio, en esa plaza donde se reúnen y socializan ya sea tomando una cerveza o haciendo freestyle. En su crew se refugian, comparten, "se rescatan" — calmarse o controlarse-, viven.

Brian y su crew se juntan en la plaza, que funciona como en otros contextos lo hacen la "vereda" y el "potrero" — descampado para jugar fútbol-, esto es, "los territorios de la conversación inconducente y del estar juntos porque sí. Espacios donde el intercambio, el contacto y el habla son fines y no medios" (Tonkonoff, 2007: 8). A diferencia de lo que explica el autor, en el caso de Brian el juntarse en la plaza además de pasar el tiempo es el momento en el cual hacen freestyle, piensan cómo grabar un tema para subir a su canal de Youtube, organizan una nueva

${ }^{7}$ Ganador de Premio Grammy Latino 2001: Mejor Álbum Rap/Hip-Hop por “Un Paso A La Eternidad".

${ }^{8}$ Primer Campeón de Freestyle Argentino. 
presentación en un festival o discuten las dinámicas de los talleres de Hip Hop para los más pequeños del barrio.

La característica de esta música, que consiste en "hablar algo de la calle", es la marca que nuclea a estos jóvenes y funciona como límite social para construir su identidad. La música reúne una comunidad como forma de expresión más allá de las diferencias idiomáticas y geográficas.

Me acuerdo que en Canal 13 pasaban un programa que se llamaba "La trasnoche del 13" y ahí pasaban películas de rap, y vi "Juice" y "Los reyes de la calle", y dije "loco, esto es lo mismo que mi barrio pero con otro ritmo y es la misma ropa pero más ancha”. Entonces digo, "uh, qué onda con esto, ¡está bueno!", aparte yo que no sabía cantar, o sea, es rapear, y aparte no había escuchado nada en castellano, pero yo me daba cuenta que estaban hablando de algo de la calle. O sea, el sentimiento transmite mucho, vos podés escuchar una canción en otro idioma con los ojos cerrados y según la rítmica y el lamento que le ponga el chabón ${ }^{9}$ vos sentís de qué carajo está hablando más o menos (entrevista a Malajunta, abril 2016).

En las entrevistas, muchos de nuestros informantes coinciden que el Hip Hop se importó desde Hollywood a través de películas de breakdance. Estos jóvenes construyen sus identidades mediante ciertos consumos culturales, entendidos como "el conjunto de procesos socioculturales en que se realiza la apropiación y los usos de los productos" (García Canclini, 1995: 108). Entonces, por esos consumos culturales, como por ejemplo el filme citado por Malajunta, comenzaban a hacer propio lo ajeno porque se animaban a rapear, y sin saber el idioma —inglés - podían entender lo que se transmitía e identificarse con el barrio del Bronx, cuna del Hip Hop, y las desigualdades sociales que éste representa. Los productos de la industria del Hip Hop difundidos a través del cine hollywoodense, la música y los modos del decir, son apropiados y resignificados en las jergas propias de estos jóvenes locales

\footnotetext{
${ }^{9}$ Se usa como vocativo para referirse a una persona a la que no se conoce o de la que se desconoce su nombre. Es sinónimo de "pibe" o "muchacho".
} 
que utilizan la plaza como espacio de intervención artística, al mismo tiempo fortalecen lazos sociales en las comunidades que habitan. La plaza opera como centro en el que se construyen identificaciones, los jóvenes resisten y reconfiguran el espacio urbano a través del Hip Hop de forma similar a lo que sucedía en Estados Unidos. En este sentido, el grupo identifica a aquellos que realizan la misma actividad cultural como "pares", más allá de las fronteras geográficas, concibiéndose como integrantes de una "comunidad imaginada" (Anderson, 1983) de la que todos forman parte.

\section{El blanco ${ }^{10}$ es el negro. Los sentidos de la violencia}

Luego de las entrevistas en profundidad realizadas, de compartir materiales referidos al Hip Hop, asistir a diferentes festivales y eventos que organizaron, algunos de estos jóvenes pasaron a ser nuestros informantes y así fue cómo nos invitaron a compartir sus presentaciones:

Hola, te escribo. Escucháme, este sábado que viene hacemos alto evento en el barrio. Fijate pero tendrías que venir, pusimos punto de encuentro en Av. Cruz y Mariano Acosta a las 3 de la tarde y ahí vamos a Plaza Fátima. Estamos a full con esto porque hay de todo, fijate en el Facebook y invitá (mensaje de Whatsapp, invitación de Brian al Festival de RAP Mi cara, mi ropa y mi barrio, no son delito, sábado 04/06/2016 en Plaza Fátima, Villa Soldati).

El Festival de RAP Mi cara, mi ropa y mi barrio, no son delito es un evento barrial e itinerante que se realiza en diferentes villas desde el año 2016. Principalmente tiene el propósito de difundir el Hip Hop, ubicado en un lugar periférico de la industria cultural argentina ya que es la cumbia — ritmo tropical— la música popular por excelencia; se construye como un espacio de expresión artística que busca visibilizar la reivindicación pública de derechos y la lucha contra la violencia institucional de la que estos jóvenes son víctimas frecuentes. El origen, según uno de los organizadores:

\footnotetext{
${ }^{10}$ Sinécdoque de "tiro al blanco".
} 
Nos juntamos un día los tres para ver qué podíamos hacer porque se reflejaba mucho el abuso de autoridad, la mano dura que se estaba viviendo a través de la fuerza policial. Pensábamos en atraer a los pibes del barrio sin importar la edad pero sí para generar conciencia de la violencia institucional que se vive hasta hoy en día (entrevista a Lucas, uno de los tres organizadores del Festival de RAP Mi cara, mi ropa y mi barrio no son delito, octubre 2016).

Cuando Lucas habla de "abuso de autoridad, la mano dura que se estaba viviendo a través de la fuerza policial"; que el fin de su festival es "generar conciencia de la violencia institucional que se vive hasta hoy en día”, ubica al Hip Hop como un arte popular que no puede pensarse independiente de la realidad social de segregación y de marginación a la que se ven expuestos (Tijoux, Facuse y Urrutia, 2012), porque ya desde sus inicios el Hip Hop fue más que solo música, encapsulaba las ideas de comunidad e intercambio (Castillo-Garsow y Nichols, 2016). Y estas mismas ideas están presentes, en sus palabras:

Muchos festivales son muy diferentes a nosotros, lo hacen con batallas de gallos y un estilo más agresivo y nosotros teníamos ganas de generar un grito y decir "acá estamos, somos nosotros, no queremos más que nos caguen a palos, que nos den pocos turnos en los hospitales públicos, no queremos que en los colegios públicos no haya vacantes, queremos bancos adecuados para estudiar, más medicamentos, más atención”, y sobre todo esto, que la policía a los pibes de la esquina los cagaba a palos directamente, no es que los revisaba, les pegaba por ser negritos, por usar ropa deportiva y usar gorra (entrevista a Lucas, noviembre 2016).

La violencia ejercida por las fuerzas de seguridad, que "les pegaba por ser negritos, por usar ropa deportiva y usar gorra”, puede ser leída en clave de Reguillo, donde "ser un joven de los barrios periféricos o de los sectores marginales se traduce en ser 'violento', 'vago', 'ladrón', 'drogadicto', 'malviviente' y 'asesino', en potencia o real” (2012: 123). Ellos lo saben, ellos lo viven y perciben así. En los barrios vulnerados en los que trabajamos, la detención arbitraria de jóvenes es práctica habitual: 
Entrevistadora: ¿Me dijiste que el otro día te paró la policía?

Elio: Sí, pero no me hizo nada.

Entrevistadora: Pero, ¿te paró porque sí?

Elio: De frente mar y me revisó en medio de la gente así.

Entrevistadora: ¿Por qué?

Elio: Yo que sé, capaz porque estaba encapuchado y con la visera, viste.

Entrevistadora: ¿Y te revisaron de una o primero te pidieron el DNI

[Documento Nacional de Identidad]?

Elio: Me pusieron contra la pared, me revisaron, me dijo que me siente y me saque la gorra y que no le falte el respeto, y yo no le había dicho nada al gil.

Durante la entrevista, en febrero 2016, Elio dijo que nunca estuvo detenido pero que siempre es sospechoso "capaz porque estaba encapuchado y con la visera”, aseguró; la identificación criminal atraviesa los tiempos y continúa vigente, adolescentes y jóvenes pobres lo saben, lo sufren, y nuestros informantes buscan cobijarse en la música y en el encuentro, que se constituyen en lugar social desde el que describen su realidad, su actualidad.

De este y otros relatos de los jóvenes entrevistados se desprende que ellos reconocen que deben lidiar a diario con el estereotipo que señala al joven habitante de barrios populares, principalmente varón, morocho y villero que viste ropa deportiva, como delincuente por excelencia, imaginario que se vehiculiza tanto en los medios masivos de comunicación como en las conversaciones sociales en Argentina y en otras regiones de América Latina (Arfuch, 1997; Rey, 2005; Da Porta, 2008; Martini, 2009). En este sentido, la vestimenta funciona como estigma (Goffman, [1963] 1998) en tanto atributo desacreditador que los convierte en "sujetos peligrosos".

En las letras de las canciones se postula una actitud contestataria frente a esta estereotipación negativa:

\footnotetext{
Yo no soy un gangsta

pero empilcho como tal como en donde vivo

yo no soy un gangsta
} 
pero esta mierda es real porque es lo que vivo

(Trap ${ }^{11}$ "Como en donde vivo", Malajunta ${ }^{12}$ ).

A su vez, la vestimenta funciona como signo ideológico (Voloshinov, [1929] 1992) en el que se entrecruzan diversos sentidos. Tanto Brian, Elio, Aníbal, Dj Leica y Lucas como Malajunta, al tiempo que buscan diferenciarse de aquellos que se dedican a actividades delictivas comparten el uso de la misma ropa, pero esto significa no ya una ligazón a prácticas ilegales sino una pertenencia común al barrio que transitan. Ellos despliegan acciones en la calle; como por ejemplo realizar algún acto "fuera de lugar, hacer bardo" (Rodríguez Alzueta, 2017), pintar un grafiti, quemar un objeto de la vía pública, "aguantar" (Alabarces y Garriga Zucal, 2007) en un enfrentamiento con otra banda o la policía, pintar o rayar un auto con el nombre de la crew —o de la "enemiga"-; en otras palabras, la transgresión a la ley los jóvenes la viven como un desafío hecho afirmación para consolidar la legitimidad de pertenencia al grupo donde "hacer bardo, según los jóvenes, es pasar a la ofensiva, provocar al otro ... se lo provoca para reclamar su mirada" (Rodríguez Alzueta y Garibaldi Noya, 2016: 138).

La vida social de estos varones jóvenes no debe entenderse en un sentido esencialista sino que se trata de "configuraciones que expresan procesos de larga duración y de articulaciones múltiples: económicas, sociales, políticas y culturales; un escenario no es simplemente un lugar, es siempre un lugar significado (De Certeau, 1996, en Reguillo, 2005: 63). En CABA, los expedientes abiertos en los juzgados de menores en el ańo 2012 fueron 3,276, y en los juzgados criminales 31,597 , lo que arroja una proporción sensiblemente menor, dado que sólo uno de cada trece jóvenes corre el riesgo de ser capturado por el sistema penal (Guemureman, 2016). "Las probabilidades no se distribuyen en forma aleatoria, sino que el sistema penal es selectivo y apresa determinados tipos de jóvenes: los de sectores socialmente vulnerables ocupan el primer lugar en este aspecto" (Guemureman,

${ }^{11}$ El Trap es un género musical de los 90 que comenzó en el sur de Estados Unidos. Es una mezcla de Hip Hop con música electrónica. Se caracteriza por su sonido agresivo y contenido lírico. ${ }^{12}$ Malajunta es un referente del trap nacional. "Como en donde vivo" en YouTube: https:// www.youtube.com/watch?v=rcGS_OXRNcw 
2016: 14). La Base General de Datos de Niños, Niñas y Adolescentes (BGD) de la Corte Suprema de Justicia de la Nación, y la Procuraduría de Violencia Institucional (Procuvin) de la Procuración General de la Nación, realizaron un informe conjunto en el año 2015 que incluía las internaciones y traslados en materia penal de niños, niñas y adolescentes durante los ańos 2013 y 2014, donde se muestra que nueve de cada diez niños, niñas y adolescentes con órdenes judiciales de internación o privación de libertad son varones. El promedio de edad es 16 años. Y nueve de cada diez niños, niñas y adolescentes que fueron internados judicialmente por causas penales son argentinos, de los cuales 45\% declaró vivir en la Ciudad Autónoma de Buenos Aires, 54\% en la Provincia de Buenos Aires, y sólo 1\% reside en otra provincia del país (BGD y Procuvin, 2015).

En cierta medida la relación con el delito forma parte de la multidimensionalidad de su "experiencia social", que no implica tan sólo un acceso restringido a los recursos que permiten sobrevivir sino también una participación desfavorable en los sistemas de poder y prestigio social (Miguez, 2008). Las canciones narran micro historias de vida de amigos o familiares con trayectorias delictivas, las motivaciones y el dramatismo, y reivindican la "salida" de esa situación a través de la revalorización del trabajo, la educación y la libertad:

Cabeza... tenía 18

un par de gustos caros y dos amigos rochos

tenía un 38 andaba medio mocho

y arriba de un gassel ...salían re de corcho

tenía respeto en el barrio porque era un re ladrón

caminaba y siempre al lado sus ñeris eran re dos

... un enfrentamiento a tiros con la voz de alto

y en la fuga su amigo murió dentro del auto

zafo y dejó a su ñeri en la puerta del hospital

llorando su otro compa le decía acelera

pero a la semana allanamiento policial

dejó a su amigo re embroncado directo al penal 


\section{ESTRIBILLO}

vivan los pibes cabeza

sobre todo los que piensan

se enderezan cheto y salen de esa!

... la lancha que pasea encima la P.F.A

por ahora la tarea es que en meses no lo vean

su amigo le escribe una esquela acá está horrible

disfrutá cabeza de que vos sos libre!

dedicate a tu familia y a tu hija

... de delincuente a empleado y también peón

se anotó en el secundario y lo terminó

ahora su apodo en el barrio es «QUÉ HACÉS CAMPEÓN»

(Trap "Pibes cabeza" (2015), Malajunta ${ }^{13}$ )

Durante la entrevista a Malajunta (abril, 2016), él explicó que "cabeza puede ser tu amigo o podés ser vos"; recurriendo a metáforas para darle mayor fuerza expresiva. Estos jóvenes que hacen Hip Hop interactúan con metáforas de la vida cotidiana (Lakoff y Johnson, 1991) porque "toda metáfora implica la búsqueda de un modelo en otro lado, en otra serie, una conexión isomórfica que nos permita explicarnos, ordenar el sentido frente a algo que nos resulta nuevo, inexplicable, o por lo menos no fácilmente formalizable" (Ford, 1994: 43). En la medida que "el significado siempre es significado para alguien, las metáforas básicamente son recursos para entender" (Lakoff y Johnson, 1991 [1980]: 226). Así es como estos jóvenes utilizan constantemente metáforas de la vida cotidiana durante el freestyle, al mismo tiempo que se valen de la metáfora para llamar batallas — rituales de interacción a través de la improvisación-a esos encuentros.

13 "Pibes cabeza" (2015) en YouTube: https://www.youtube.com/watch?v=uBPk-Loyct0 


\section{A modo de cierre}

En estas breves líneas hemos procurado dar cuenta de ciertas formas en que algunos varones jóvenes de sectores populares urbanos construyen un aspecto de su identidad en torno a una expresión artística en común. A través de los modos de habitar un territorio, los usos y la circulación que estos jóvenes le dan al Hip Hop, y las formas de expresión artística para denunciar el abuso y la violencia institucional, por ejemplo en el Festival de Rap mi cara, mi ropa y mi barrio no son delito, nuestros jóvenes entrevistados sienten que logran constituirse como actores sociales y sujetos de derechos.

Nuestros informantes han crecido y se están desarrollando en contextos de desigualdad social acentuada. Entre las desventajas estructurales y violencias materiales y simbólicas que enfrentan cotidianamente, los jóvenes disputan participación y protagonismo en la dinámica cultural mediante esta práctica. A través de la música y el arte, denuncian la estigmatización y visibilizan las situaciones de violencia que viven cotidianamente. El Hip Hop funciona en este sentido como una práctica que permite construir colectivos culturales como espacios de expresión, identificación y pertenencia en aquellos territorios atravesados por la pobreza y la conflictividad social.

Jóvenes como Brian, Elio, Aníbal y Dj Leica, entre tantos otros, se apropian del Hip Hop como género y modo comunicacional, a través del cual reafirman su identidad y "batallan" el propio sentido de lo que significa ser varón joven de sectores populares urbanos con derechos vulnerados. De esta manera, en la medida que su estructura social está permeada de violencias, ellos se valen del Hip Hop — como práctica que se configura como cultural- porque sienten que durante los encuentros de freestyle y compartiendo sus raps en el Festival mi cara, mi ropa y mi barrio no son delito de alguna manera resisten aquellas violencias que los atraviesan en su vida cotidiana y, al menos en el escenario, sienten que son parte de una comunidad más amplia, un espacio de contención social en el que encuentran el reconocimiento de sus derechos, vulnerados sistemáticamente en otras instancias. 


\section{Bibliografía citada}

Alabarces, P. y J. Garriga Zucal, 2007, "Identidades Corporais: entre relato o aguante", Campos. Revista de Antropología Social, vol. 8, núm. 1, UFP, Paraná.

Anderson, B., 1993 [1983], Comunidades imaginadas. Reflexiones sobre el origen y la difusión del nacionalismo, FCE, México.

Arfuch, L., 1997, Los jóvenes en la crónica policial, Unicef, Buenos Aires. Castillo-Garsow, M. y J. Nichols, 2016, La Verdad: An International Dialogue on Hip Hop Latinidades, The Ohio State University Press, Columbus.

Cuche, D., 1996, "Cultura e Identidad", en La noción de Cultura en las Ciencias Sociales, capítulo VI, Nueva Visión, Buenos Aires, pp. 106-113.

Da Porta, E., 2008, "Jóvenes, exclusión y narrativas mediáticas: el rostro del delito", en Más allá de víctimas y culpables. Relatos de experiencias en seguridad ciudadana y comunicación-América Latina, Friedrich Ebert Stiftung, CCC, Bogotá.

Ford, A., 1994, Navegaciones. Comunicación, cultura y crisis, Amorrortu, Buenos Aires.

García Canclini, N., 1995, Consumidores y ciudadanos. Conflictos multiculturales de la globalización, Grijalbo, México.

Goffman, E., 1963, "Estigma e identidad social", en Estigma. La identidad deteriorada, Amorrortu, Buenos Aires.

Guemureman, S., 2016, Adentro y afuera. Juventudes, sistema penal y políticas de seguridad, Colección Grupos de Trabajo, Grupo Editor Universitario, Clacso, Buenos Aires.

Kessler, G., 2012, "Las consecuencias de la estigmatización territorial. Reflexiones a partir de un caso particular", Espacios en blanco, Serie indagaciones, vol. 22, núm. 1, enero-junio, Tandil.

Lakoff, G. y M. Johnson, 1991 [1980], Metáforas de la vida cotidiana, Ediciones Cátedra, Madrid.

Margulis M. y M. Urresti, 1998, "La construcción social de la condición de juventud”, en H. Cubides, M. Laverde y C. Balderrama (editores), Viviendo a Toda. Jóvenes, territorios culturales y nuevas sensibilidades, Siglo del Hombre, Bogotá, pp. 3-21. 
Martini, S., 2009, "El delito y las lógicas sociales. La información periodística y la comunicación política”, en Stella Martini y Marcelo Pereyra (directores), La irrupción del delito en la vida cotidiana, Biblos, Buenos Aires.

Miguez, D., 2008, Delito y Cultura: los códigos de la ilegalidad en la juventud marginal urbana, Biblos, Buenos Aires.

Reguillo, R., 2005, Horizontes fragmentados. Comunicación, cultura, pospolítica. El (des)orden globaly sus figuras, ITESO, Guadalajara, Jalisco.

Reguillo, R., 2012, Culturas juveniles. Formas politicas del desencanto, Siglo XXI, Buenos Aires.

Rey, G., 2005, El cuerpo del delito, Friedrich Ebert Stiftung, CCC, Bogotá.

Rodríguez Alzueta, E., 2017, “Consumo y delito: si no hay futuro hay joda”, en E. Rodríguez Alzueta (compilador), Hacer Bardo. Provocaciones, resistencias y derivas de jóvenes urbanos, Malisia, La Plata.

Rodríguez Alzueta, E. y Garibaldi Noya, N., 2016, "Palabra y potencia: estrategias gramaticales contra la estigmatización”, en E. Rodríguez Alzueta (compilador), Hacer bardo. Provocaciones, resistencias y derivas de jóvenes urbanos, Malisia, La Plata.

Roldán, N., 2016, "Los jóvenes en los huecos urbanos: graffitis, hip hop y revueltas callejeras”, en E. Rodríguez Alzueta (compilador), Hacer Bardo. Provocaciones, resistencias y derivas de jóvenes urbanos, Malisia, La Plata.

Tijoux, M. E., M. Facuse y M. Urrutia, 2012, "El Hip Hop: ¿Arte popular de lo cotidiano o resistencia táctica a la marginación?”, Polis, Revista Latinoamericana, vol. 11, núm. 33.

Tonkonoff, S., 2007, “Tres movimientos para explicar porqué los pibes chorros visten ropas deportivas", en Sociología Ahora, Siglo XXI, Buenos Aires.

Voloshinov, V., 1992 [1929], El marxismo y la filosofía del lenguaje, capítulos 1 y 2 de $1^{\text {a }}$. parte, Alianza, Madrid. 


\section{Documentos}

Dirección General de Estadística y Censos del Gobierno de la Ciudad de Buenos Aires, Mayo 2017, Encuesta Anual de Hogares, Ciudad de Buenos Aires, Base usuarios 2016.

Informe "Diagnóstico de la Ciudad de Buenos Aires, ¿cómo está tu comuna?", 2011, [en línea] disponible en https://unidadpopularcaba.org.ar/2015/04/20/diagnostico-dela-ciudad-de-bs-as-como-esta-tu-comuna [fecha de consulta: 20 de mayo de 2018].

Informe de gestión "Niñez, adolescencia y Salud mental en la Ciudad de Buenos Aires", Ministerio Público Tutelar, 2011, pp. 189195, [en línea] disponible en http://www.mptutelar.gob.ar// sites/default/files/InformeAnual2011.pdf [fecha de consulta: 20 de mayo de 2018].

Informe "La Pobreza monetaria en la niñez y la adolescencia en Argentina”, Unicef, 2017, [en línea] disponible en https:// www.unicef.org/argentina/sites/unicef.org.argentina/ files/2018-03/Monitoreo-La_pobreza_monetaria_en_la_ ninez_y_adolescencia_2017.pdf [fecha de consulta: 20 de mayo de 2018].

Informe "Procesamiento y sistematización de la Base de niños, niñas y adolescentes institucionalizados", 2015, realizado en conjunto por la Base General de Datos de Niños, Nińas y Adolescentes (BGD) de la Corte Suprema de Justicia de la Nación y la Procuraduría de Violencia Institucional de la Procuración General de la Nación (Procuvin), [en línea] disponible en http://www.csjn.gov.ar/bgd/verMultimedia?data=1864 [fecha de consulta: 20 de mayo de 2018]. 